\title{
Visual localisation in patients with occipital infarction
}

\author{
RW ROSS RUSSELL, N BHARUCHA \\ From the Institute of Neurology, National Hospital for Nervous Diseases, Queen Square, St. Thomas' \\ Hospital, and Moorfields Eye Hospital, London UK
}

SUMMARY Visually directed pointing has been examined in a group of patients with occipital lobe infarction and in an age-matched control group. The visual field ipsilateral to the infarct showed normal localisation; there was no evidence that right sided infarction produced a bilateral disturbance. In quadrantanopia the spared quadrant on the affected side showed abnormal localisation in a few patients but this was not consistently associated with right or left sided defects. The majority of patients were able to detect a flashing light within the blind portion of the field although the same stimulus could not be seen during conventional perimetry. Some patients could localise the stimulus normally.

Patients who had lost the ability to point accurately to an object although still able to see it normally were described by Holmes ${ }^{1}$ in his account of the syndrome of visual disorientation; they were battle-casualties and had bilateral penetrating wounds of the parieto-occipital region, sometimes involving the splenium. Riddoch ${ }^{2}$ later showed that the syndrome could be restricted to one half-field and Cole, Schutta and Warrington ${ }^{3}$ in a unilaterally affected patient confirmed that the difficulty in pointing was not due to proprioceptive loss in the reaching limb since it was present when either the right or the left arm was used.

In contrast there are other patients who have lost the ability to see normally in part of the field but who retain some residual visual function. Riddoch, ${ }^{4}$ for example, described patients who could detect a stimulus in the affected field, when it was moving but not when it was stationary. Patients who, after localised brain damage, are still able to appreciate the orientation, movement and shape of objects within a "blind" field have excited much recent interest. ${ }^{5}$ They provide insight into aspects of visual perception of which the patients may not normally be aware and which may be operating at a subcortical or brainstem level.

The present report on the reaching and localising abilities of patients with vascular lesions of the

Address for reprint requests: Dr RW Ross Russell, Dept of Neurology, St Thomas' Hospital, London SE1 7EH, UK.

Received 26 May 1983 and in revised form 18 August 1983 Accepted 12 September 1983 occipital lobe attempts to answer a number of questions; firstly, is normal localising ability preserved in "seeing" portions of the visual field, for instance, in the opposite half field, or in the case of a quadrantanopia, the spared quadrant of the affected field? Secondly, are there any differences between those with right and left hemianopias? Thirdly, what proportion of patients with occipital vascular lesions can be shown to retain detecting and localising ability in the blind field; lastly, is this ability associated with a particular side?

\section{Patients and methods}

The control group consisted of patients who had been admitted to the National Hospital for Nervous Diseases with diseases which had not affected the brain or eyes. This group had a mean age of 56 years ( 7 men and 3 women). In the test group were 17 patients all having visual field defects consistent with unilateral occipital lobe infarction and confirmed by Goldman and Aimark perimetry and by CT scan. There were 13 men and 4 women with a mean age of 56 years. They were all right handed and none had any neurological disturbance other than a field defect. Individual field defects were: right homonymous hemianopia two patients, left homonymous hemianopia two patients, right lower quadrantanopia three patients, right upper quadrantanopia four patients, left lower quadrantanopia three patients, left upper quadrantanopia three patients. In all cases the field defects were "absolute", the patient failing to see any of the stimuli up to size $10 \mathrm{~mm}$ diameter and intensity 1.3 log.ft.Lamberts $\left(70 \mathrm{~cd} / \mathrm{m}^{2}\right)$ when tested on the Aimark perimeter in the conventional "dynamic" method.

A dark room was used for the testing of localisation. Each eye was examined separately on the Airmark perime- 
ter and the subject placed his index finger on the arc of the perimeter at the point where he thought the light spot had appeared. The right hand was used throughout. The subject kept his gaze fixed on the central cross and he was warned when a stimulus was about to be flashed. The stimulus was a $10 \mathrm{~mm}$ diameter white light spot of the brightest intensity that the perimeter could provide $(1 \cdot 3$ log. ft.Lamberts, $70 \mathrm{~cd} / \mathrm{m}^{2}$ ). The duration of the stimulus (approx. 0.5 second) was standardised by a simple shutter device using a spring and elastic band. The subject was asked to make an attempt at localisation whenever he was aware of the stimulus irrespective of whether or not he saw it clearly. He was not forced to point on each occasion. The error in localisation was then measured by readjusting the spot so that it coincided with the centre of the reaching finger tip. The error was then read off the Aimark perimeter to the nearest $2 \cdot 5^{\circ}$. Three standard points were tested in random order in each quadrant at each eccentricity $\left(10^{\circ}\right.$, $30^{\circ}, 50^{\circ}, 70^{\circ}$ and $90^{\circ}$ ). The vertical and horizontal meridians were not used. The procedure was then repeated for the other eye.

\section{Results}

\section{Normal subjects}

By combining right and left eyes six readings each representing the difference between the true and the estimated position of the stimulus were available in each subject in each of the four quadrants at each of the inner isopters $\left(10^{\circ}, 30^{\circ}, 50^{\circ}\right)$. Fewer readings were available at $70^{\circ}$ and $90^{\circ}$ because the subject sometimes failed to see the stimulus especially in the nasal field. The average individual error in each isopter and quadrant was calculated and a mean error score for this group was derived (one reading per patient) at $10^{\circ}, 30^{\circ}, 50^{\circ}$ and $70^{\circ}$.

In the control group localisation was excellent in the central parts of the field. In the periphery subjects tended to under-estimate slightly the position of the stimulus (fig 1). When the mean error scores in the upper quadrants were compared with those in the lower quadrants a significant difference was found at $30^{\circ}, 50^{\circ}$ and $70^{\circ}$, the larger errors being in the upper field (table 1).

Table 1 Mean errors (in degrees): control subjects $(n=10)$ one value per subject in each quadrant

\begin{tabular}{lllll}
\hline Eccentricity & Left field & Right field & Upper field & Lower field \\
\hline $10^{\circ}$ & 0.6 & 0.6 & 0.5 & 0.6 \\
$30^{\circ}$ & 2.0 & 2.3 & 2.6 & $1 \cdot 0^{*}$ \\
$50^{\circ}$ & 5.5 & $5 \cdot 0$ & 6.3 & $4 \cdot 2^{*}$ \\
$70^{\circ}$ & 7.5 & 6.8 & 10.4 & $3.9^{*}$ \\
\hline
\end{tabular}

*Significant difference between upper and lower fields (mean difference at $30^{\circ} 1.6(\mathrm{SD} 1.3) \mathrm{t}=4.16 \mathrm{p}<0.01$; mean difference at $50^{\circ} 2.1($ SD 1.2$) t=5.6 \mathrm{p}<0.01$; mean difference at $70^{\circ} 6.4$ (SD 4.1 ) $\mathrm{t}=5.0 \mathrm{p}<0.01$ )

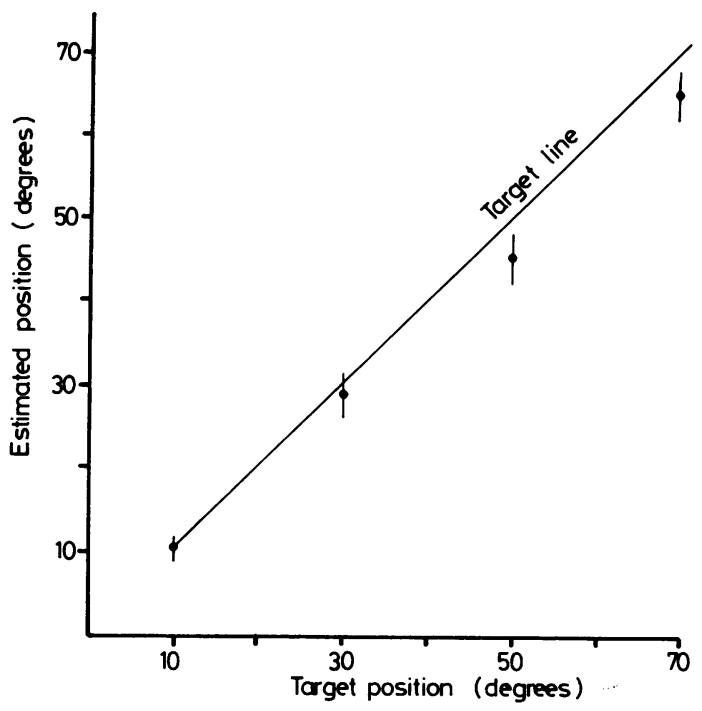

Fig 1 Combined results from all normal subjects. Note tendency to under-estimate target position at outer isopters (mean $\pm 2 S D)$.

\section{Patient group}

(a) Unaffected half field

With two exceptions described below the accuracy of localisation in the intact half-field was normal and there was no suggestion that a unilateral lesion, either right or left-sided, could give rise to bilateral disturbance of reaching (table 2). There were two patients in whom perimetry revealed only a unilateral defect yet a bilateral abnormality of localisation was found (fig 2). However, when the CT scans were examined bilateral occipital cortex lesions were visible in both cases.

Table 215 patients with unilateral field defect. Mean errors (in degrees) in the unaffected half field $10^{\circ} 30^{\circ} 50^{\circ}$ isopters (2 patients with bilateral infarcts omitted)

\begin{tabular}{|c|c|c|c|}
\hline & $10^{\circ}$ & $30^{\circ}$ & $50^{\circ}$ \\
\hline $\begin{array}{l}\text { Right hemianopias } \\
\text { and quadrantanopias } \\
\text { mean right }\end{array}$ & $\begin{array}{l}1.5 \\
0.6 \\
0.3 \\
0.5 \\
1.5 \\
1.0 \\
0.9 \\
0.6 \\
0.4 \\
0.8\end{array}$ & $\begin{array}{l}3 \cdot 0 \\
1 \cdot 0 \\
2 \cdot 8 \\
1 \cdot 5 \\
2 \cdot 3 \\
6 \cdot 2 \\
2 \cdot 2 \\
1 \cdot 4 \\
2 \cdot 25 \\
2 \cdot 5\end{array}$ & $\begin{array}{l}3 \cdot 3 \\
2 \cdot 75 \\
6 \cdot 25 \\
3 \cdot 0 \\
4 \cdot 5 \\
7 \cdot 5 \\
4 \cdot 7 \\
4 \cdot 6 \\
3 \cdot 0 \\
4 \cdot 4\end{array}$ \\
\hline $\begin{array}{l}\text { Left hemianopias } \\
\text { and quadrantanopias }\end{array}$ & $\begin{array}{l}0.5 \\
0.2 \\
0.8 \\
1.6 \\
0.7 \\
0.8 \\
0.8\end{array}$ & $\begin{array}{l}2 \cdot 25 \\
3 \cdot 0 \\
3 \cdot 0 \\
6 \cdot 2 \\
2 \cdot 3 \\
4 \cdot 25 \\
3 \cdot 4\end{array}$ & $\begin{array}{l}5 \cdot 5 \\
3 \cdot 8 \\
4 \cdot 2 \\
9 \cdot 2 \\
5 \cdot 0 \\
7 \cdot 2 \\
5 \cdot 8\end{array}$ \\
\hline
\end{tabular}




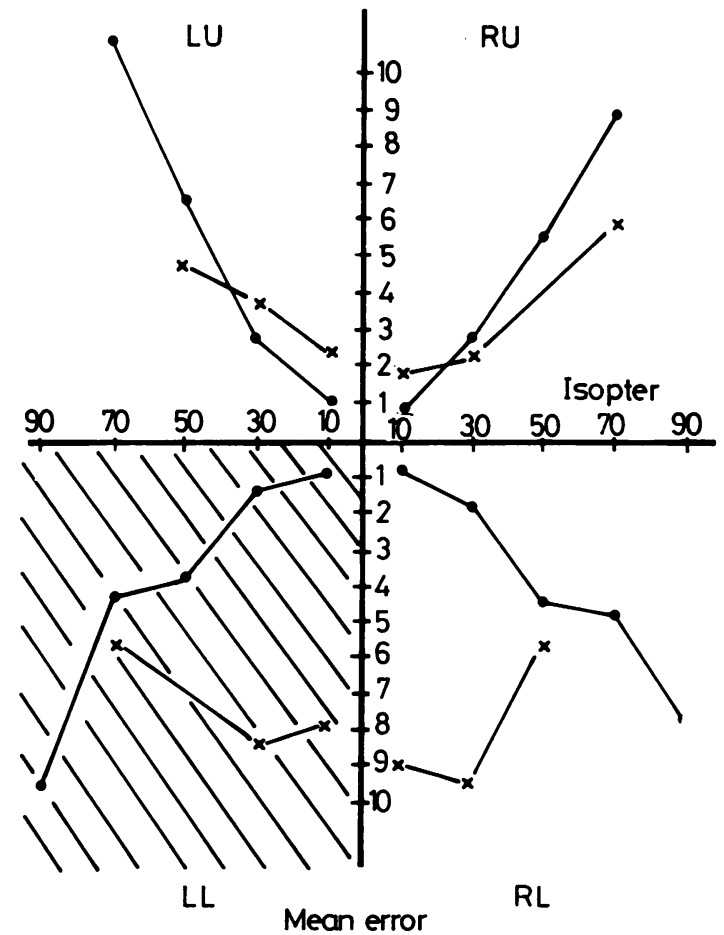

Fig 2 A single patient with left inferior quadrantanopia. This patient made large errors in the blind quadrant (shaded) but equally large errors in the right lower quadrant where no field defect was found on perimetry. Bilateral lesions on CT scan. $x=$ patient $\bullet=$ control group.

\section{(b) Affected half field $(\mathrm{n}=13)$}

\section{Spared quadrant}

In all patients with quadrantanopia localising ability was examined in the intact quadrant adjacent to the blind quadrant. Mean error scores in this quadrant for the whole group were within the normal range; there was a total of five abnormal responses having more than twice the mean error for controls compared with 34 normal attempts (table 3 ). This is not a significantly greater proportion than in the control group. In individual patients the magnitude of the errors was much greater than that of the controls, in some cases up to ten times the mean error. Inaccurate responses were distributed equally between those with right and left sided defects; four out of 21 responses were inaccurate in patients with upper field defects compared with one out of 18 in patients with lower defects.
Table 3 Accuracy of localisation in spared quadrant of the affected field in 13 patients with quadrantanopia. 3 readings per patient $\left(10^{\circ}, 30^{\circ}\right.$ and $50^{\circ}$ isopters) (Abnormal response $=$ mean error of more than twice mean error for age-matched controls)

\begin{tabular}{|c|c|c|}
\hline & $\begin{array}{l}\text { Normal } \\
\text { responses }\end{array}$ & $\begin{array}{l}\text { Abnormal } \\
\text { responses }\end{array}$ \\
\hline $\begin{array}{l}\text { Right lower quadrantanopia } \\
\text { (3 patients) }\end{array}$ & 9 & 0 \\
\hline Right upper quadrantanopia & 9 & 3 \\
\hline Left upper quadrantanopia & 8 & 1 \\
\hline Left lower quadrantanopia & 8 & 1 \\
\hline All right sided defects & 18 & 3 \\
\hline $\begin{array}{l}\text { All left sided defects } \\
\text { ( } 6 \text { patients) }\end{array}$ & 16 & 2 \\
\hline All upper defects & 17 & 4 \\
\hline $\begin{array}{l}\text { All lower defects } \\
\text { (6 patients) }\end{array}$ & 17 & 1 \\
\hline
\end{tabular}
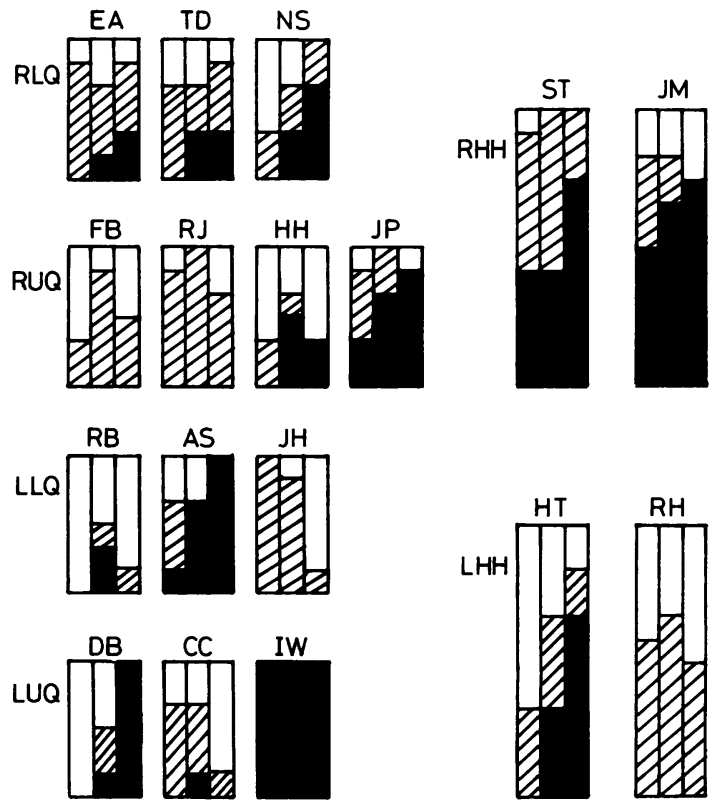

Fig 3 Summary of results in blind field in all patients.

Unshaded area $=$ normal localisation $(<2 \times$ mean error of controls)

hatched area $=$ inaccurate localisation $(>2 \times$ mean error of controls)

Black area $=$ no response.

\section{"Blind" quadrant or half field}

If the patient was unable to see anything in the affected field he was asked not to point. However of 17 patients only one failed to perceive any stimuli within the blind field. Others reported a diffuse glow 


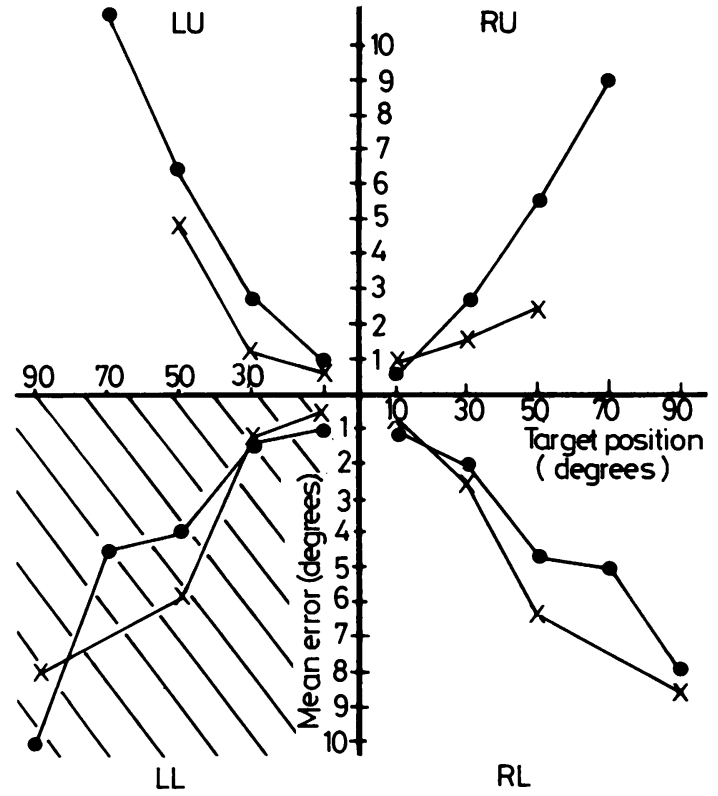

Fig 4 A single patient with left inferior quadrantanopia. The patient showed normal localisation in the blind quadrant (shaded) $x=$ patient $\bullet=$ control group.

in response to the stimulus and they were asked to attempt to locate it in the usual manner.

Localising ability was assessed in three regions of the blind field: inner $\left(10^{\circ}\right.$ isopter $)$, middle $\left(30^{\circ}\right.$ and $50^{\circ}$ isopter) and outer $\left(70^{\circ}\right.$ and $90^{\circ}$ isopter) (fig 3 ).

The proportion of negative responses was greatest in outer parts of the field and the accuracy of localisation was also worse peripherally improving progressively towards the central regions. Some patients localised well throughout the blind quadrant (fig 4). In patients with right sided field defects normal responses (less than twice mean error for controls) constituted approximately $30 \%$ while in those with left sided defects over $50 \%$ were normal. Because of the small numbers the difference was not significant. In the quadrantanopic group responses were no more accurate in upper than in lower quadrantanopias. It can be estimated by comparing relative areas that a subject pointing at random would achieve normal localisation in inner isopters once in 2000 attempts, in middle isopters once in 400 attempts and in outer isopters once in 200 attempts.

\section{Discussion}

To point accurately to a small stimulus briefly displayed within the field of vision while maintaining a steady forward visual fixation requires the ability to detect the stimulus, to orientate it relative to the point of fixation and to move the pointing finger to the correct spot. In real life reaching involves a further element of distance judgment in the sagittal plane which was not present in the test situation since the subjects knew that all stimuli were equidistant.

The present series of normal subjects and patients show that under physiological as well as pathological conditions reaching ability is better in the central than in the peripheral isopters, related presumably to the relatively large region of the striate cortex receiving projections from the central field. In the periphery normal subjects showed a consistent tendency to reach more accurately below than above the horizontal meridian. The reason for this is not clear but it may be relevant that in the course of normal activity the majority of reaching tasks involve the lower rather than upper field.

In two patients a defect in localisation in a half field was detected in the absence of visual field loss on perimetry. However in both cases bilateral occipital lesions were found by CT scanning. There was thus no suggestion that a unilateral lesion, either right or left sided, could give rise to a loss of reaching ability over the whole field. This strictly unilateral effect contrasts with the results of more complex tests such as those involving comparative visual judgments as with the relative position of two points, the copying of line diagrams, the unravelling of superimposed figures or recognition of objects viewed from unusual angles. ${ }^{6-8}$ Under these conditions it has been repeatedly shown that patients with right hemisphere lesions perform significantly worse than those with left.

In patients with quadrantanopia when the spared quadrant on the affected side was tested the results were variable, most patients showing excellent localisation while a few made large errors irrespective of the side of the lesion. A point of interest in this group was to compare the accuracy of reaching in upper and lower defects. Many of the original patients described by Holmes ${ }^{1}$ had loss of localising ability in the upper fields on both sides combined with loss of lower fields, suggesting that the parieto-occipital region on each side was essential for accurate localisation in the opposite half field. It might be expected that our patients with lower quadantanopias might also have more localising difficulty in their residual field than would those with upper quadrantanopias. No such difference was found possibly because the lesions in our quadrantanopic patients were occipital and affected either the upper or lower banks of the calcarine sulcus, whereas in Holmes' patients the visual radiation and the parieto-occipital cortex were damaged. 
Evidence of residual visual function in apparently blind fields has excited recent interest ${ }^{910}$ and the present series illustrates some aspects of this. The majority of patients with occipital vascular lesions are apparently able to detect a bright flashing stimulus within the blind field although unable to see the same stimulus when continuously exhibited. This phenomenon was first investigated by Bender and Krieger $^{11}$ who, before accepting it as real, considered a number of possible artefacts, including stray light and retinal neuronal interaction. They concluded that the phenomenon was not an artefact but an elementary type of visual perception. Other possible sources of error such as light scattering or rapid refixation ocular movements have been fully examined and discounted by Weizkrantz. ${ }^{10}$

In the present group of patients some evidence of residual visual function was found in perimetrically blind regions of the field either on the right or on the left side and in all types of quadrantanopia. The proportion of patients showing retention of accurate localisation was highest in those with left hemianopia but the numbers are too small to assess if this is significant. Nor is it possible to say whether retention of localising ability has any prognostic significance such as Riddoch ${ }^{4}$ found in patients with recent occipital injuries where the field loss for moving objects was smaller than for stationary objects and where it tended to become smaller over weeks of observation. Our patients were examined some weeks or months after vascular occlusion when the field changes were stable but it would be of interest to study visual localisation at an earlier stage.

Our patients consciously saw a visual stimulus in the "blind" field and were not asked to point unless they did so. We were therefore measuring the accuracy of localisation only in patients capable of detecting a visual flash. They were not examined by the forced-choice technique used by Weizkrantz and colleagues $^{9}$ to explore a more basic faculty, the preservation of visual function in the absence of conscious awareness (blind-sight). Their patient DB, following subtotal occipital labectomy, was shown to retain excellent localisation in addition to some elementary type of appreciation of form and orientation but he consistently denied seeing the stimulus at all. In further studies Weizkrant $\mathrm{z}^{10}$ has studied other patients who retain or recover some visual functions but not others. For instance, it appears that the threshold for awareness of a stimulus in the blind field is not necessarily the same for movement as for orientation. He tentatively suggests that detection, movement and figure-ground discrimination usually occur together as do localisation and orientation but that these two groups of functions may be dissociated.
The pathological and anatomical basis is still a matter for discussion. It is known that retinal projections from one half-field to the striate cortex remains strictly unilateral except for those subserving a narrow strip on either side of the vertical meridian where there are transcallosal connexions. ${ }^{12}{ }^{13}$ It has also been shown in the experimental animal that projections from the lateral geniculate body pass only to the striate cortex and secondary connections link this region with the peristriate and visual association areas so that complete removal of the striate cortex on one side would be expected to interrupt all the visual input to these regions. However, after removal of the striate cortex alone in the experimental monkey there is retention of some visually directed behaviour and this does not occur to the same extent if more anterior regions are also ablated. ${ }^{14}$ Kluver $^{15}$ showed that destriated animals could react to a change in total luminous flux and Pasik and Pasik ${ }^{14}$ later reported that animals could be trained to ignore luminance and choose brightness, colour or pattern. Retention of this type of visually directed behaviour was again dependent on the preservation of prestriate cortex. This might be explained by a retinal input by other pathways, perhaps via the pulvinar; alternatively it might be due to a separate mechanism at brain stem level. The recent demonstration ${ }^{16}$ of the preservation of visual localisation in patients after early complete hemidecortication argues for the latter view. The present study shows that a significant proportion of patients with hemianopia of vascular origin, possibly those in whom the infarct is strictly confined to the striate cortex, retain some awareness of a flashing light in the blind field and may have normal or near-normal visually directed reaching on that side. There are large individual differences between patients which cannot be adequately explained. These findings may be relevant to practical rehabilitation of these patients since one of the most striking and constant features of the experimental studies ${ }^{11}$ has been the extent to which the recovery of visually directed behaviour can be influenced by training.

We are grateful to Professor Elizabeth Warrington for her advice during the preparation of this paper.

\section{References}

' Holmes G. Disturbances of vision by cerebral lesions. $\mathrm{Br}$ $J$ Ophthalmol 1918;2:353-84.

${ }^{2}$ Riddoch G. Visual disorientation in homonymous half fields. Brain 1935;58:373-82.

${ }^{3}$ Cole M, Schutta HS, Warrington EK. Visual disorientation in homonymous half fields. Neurology (Minneap) 1962;12:257-63. 
${ }^{4}$ Riddoch G. Dissociation of visual perception due to occipital injuries with special reference to appreciation of movement. Brain 1917;40:15-57.

${ }^{5}$ Poppel E, Held R, Frest D. Residual visual function after brain wounds involving the cortical visual pathways in man. Nature 1973;243:295-6.

${ }^{6}$ Faglioni P, Scotti G, Spinnler H. The performance of brain damaged patients in spatial localisation of visual and tactile stimuli. Brain 1971;94:443-54.

${ }^{7}$ Hannay HJ, Varney NR, Benton AL. Visual localisation in patients with unilateral brain disease. $J$ Neurol Neurosurg Psychiatry 1976;39:307-13.

${ }^{8}$ Warrington EK, Taylor AM. Two categorical stages of object recognition. Perception 1978;7:695-705.

9 Weizkrantz L, Warrington EK, Sanders MD, Marshall J. Visual capacity in the hemianopic field following a restricted occipital ablation. Brain 1974;97:709-28.

${ }^{10}$ Weizkrantz L. Varieties of residual experience. QJ
Exper Psychol 1980;32:365-86.

"Bender MB, Krieger HP. Visual function in perimetrically blind fields. Arch Neurol Psychiatry 1951;65:72-9.

12 Cowey A. Projection of retina on to striate and prestriate cortex of the squirrel monkey. $J$ Neurophysiol 1964;27:366-92.

${ }^{13}$ Cowey A. Cortical maps and visual perception. $Q J$ Exp Psychol 1979;31:1-17.

${ }^{14}$ Pasik T, Pasik P. The visual world of monkeys deprived of striate cortex. Vision Research Suppl 1911;3:419 35.

15 Kluver H. Functional significance of the geniculostriate system. Biological Symposia 1942;7:253-99.

${ }^{16}$ Perenin MT, Jeannerod M. Visual function within the hemianopic field following early cerebral hemidecortication in man. Neuropsychologia 1978;16:1-13. 